\title{
ORTHODONTIC AND PROSTHODONTIC INTERRELATIONSHIP FOR A COMPREHENSIVE ESTHETIC OUTCOME
}

\author{
Arshin Hotchandani ${ }^{1}$, Hina Desai ${ }^{2}$, N. J. Nirmal ${ }^{3}$
}

\section{HOW TO CITE THIS ARTICLE:}

Arshin Hotchandani, Hina Desai, N. J. Nirmal. "Orthodontic and Prosthodontic Interrelationship for a Comprehensive Esthetic Outcome". Journal of Evolution of Medical and Dental Sciences 2014; Vol. 3, Issue 39, August 28; Page: 9913-9917, DOI: 10.14260/jemds/2014/3284

ABSTRACT: This clinical report describes an interdisciplinary approach for the coordinated treatment of a patient diagnosed with peg-shaped maxillary lateral incisors, short clinical crowns, excessive gingival display, and orthodontic malocclusion. The patient's specific esthetic expectations for the anterior maxilla were successfully met through phased treatment, including orthodontic tooth movement, and porcelain laminate veneers. Porcelain laminates can mimic the translucency of natural tooth structure and can provide colour and contour stability with minimal risk of gingival irritation, provided that proper oral hygiene and plaque control are maintained.Such coordinated interdisciplinary evaluation and treatment are necessary for improved aesthetic results in maxillary anterior areas aesthetically compromised in several aspects.

KEYWORDS: Esthetics, Peg-lateral, Porcelain Veneers, Orthodontic-prosthodontic interdisciplinary KEYMESSAGES: Interdisciplinary approach is essential to bring about a holistic outcome while restoring the anterior maxilla.

INTRODUCTION: The primary consideration in all treatment plans should be the conservation of tooth structure. Generally, the treatment of choice should be the least invasive possible that still satisfies the expected aesthetic and functional objectives. Aesthetics and function are of equal concern when restoring the anterior dentition. Modern concepts in restorative dentistry have brought new solutions through bonded porcelain veneers. This article deals with the problem of malocclusion and developmental anomaly of the lateral incisor and the management as an Interdisciplinary approach.

CASE HISTORY: A 13 year old, female patient reported for the following problems:

1. Over retained deciduous dentition.

2. Malformed lateral incisors.

3. Erupting lateral incisors in cross bite.

4. Narrow Maxillary arch.

5. Poor aesthetics while smiling.
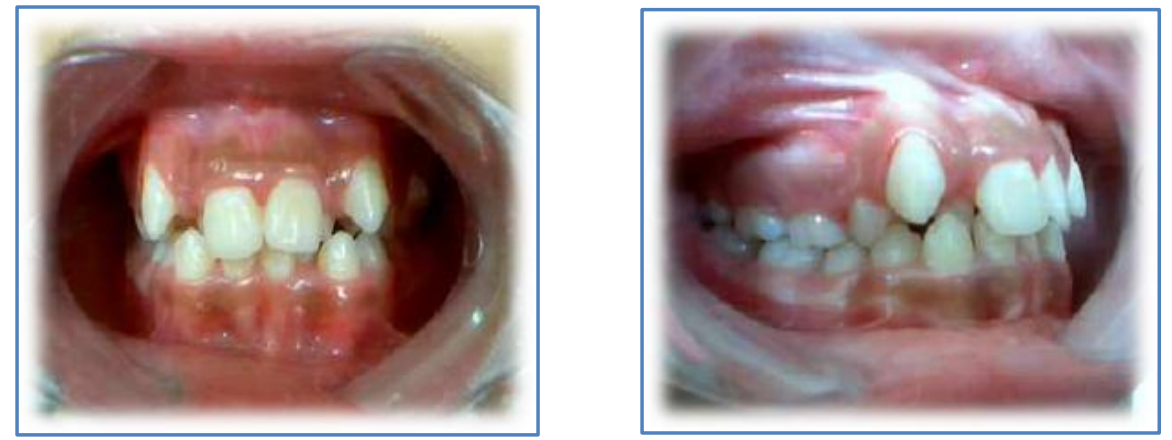


\section{CASE REPORT}

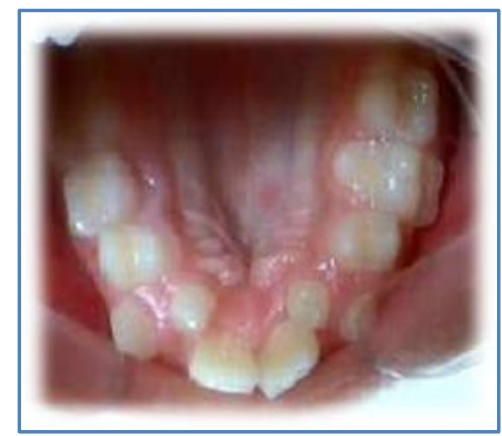

\section{Figure 1: Pre-Orthodontic Treatment}

Fixed Orthodontic therapy was carried out for her through a period of one and a half year including the use of a retainer for retention of the corrected crowding and one mandibular central Incisor extraction. Patients with narrow dental arches and high palatal vault present with reduced masticatory efficiency. Phonetics was not an encountered problem for this patient. Post Orthodontics, her corrected occlusion appeared quite satisfactory.

The patient was brought into class I angles occlusion. Adequate space was present between the maxillary lateral incisors and opposing mandibular teeth and they were out of functional contact owing to their small size. However, due to the presence of bilateral peg-lateral incisors her aesthetic quotient was incomplete.

It was decided to complete the treatment and rehabilitate the lateral incisors to normal proportions using porcelain laminates. The patient had no complains of altered phonetics or mastication.
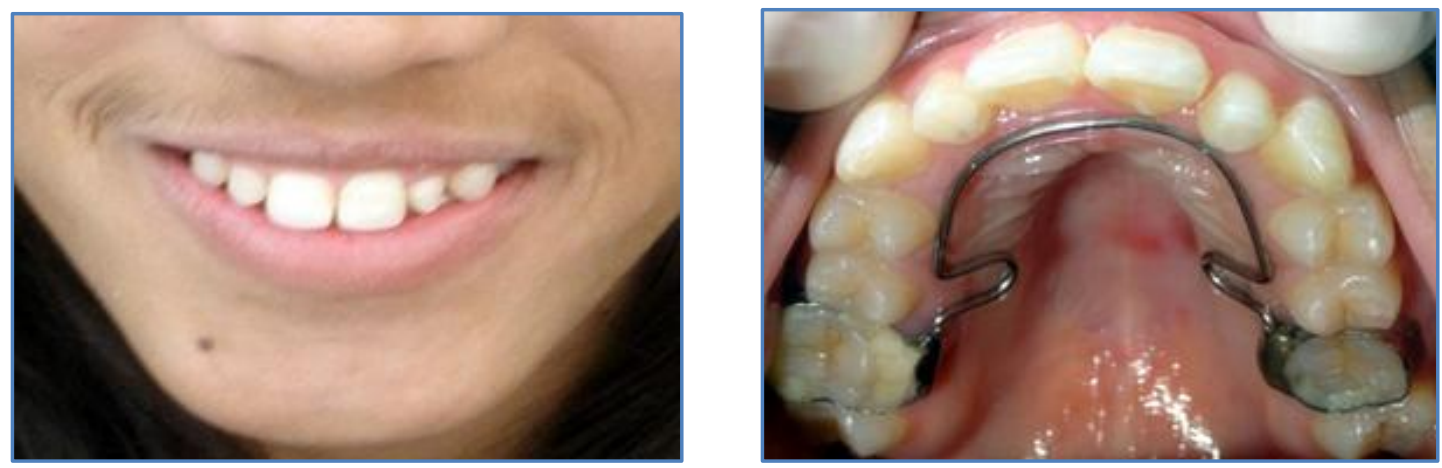

Figure 2: Post Orthodontics

Tooth Preparation: Tooth preparation consisted of preparing the labial surface approximately 0.3$0.4 \mathrm{~mm}$ intra enamel only, with an incisal wrap around ending the veneer away from the centric stops. For preparation a round ended tapered bur of medium grit (S .S. White, U.S.A) was used. Final finishing was done using a fine grit bur followed by gentle polishing of the surface with pumice to remove scratches from the prepared surface.

Tseng E.Y.et al performed a study to determine the bond strength of porcelain to dentin and compared it to enamel bond. He concluded that at $48 \mathrm{hrs}$, the enamel bond was significantly higher than that of the dentin porcelain bond. [1] 
Greater survival rate for incisal coverage (96\%) was noticed compared with no incisal coverage (85\%).With the incisal overlap design, during protrusive movement, a wider area off tooth structure is involved in stress distribution. [2]
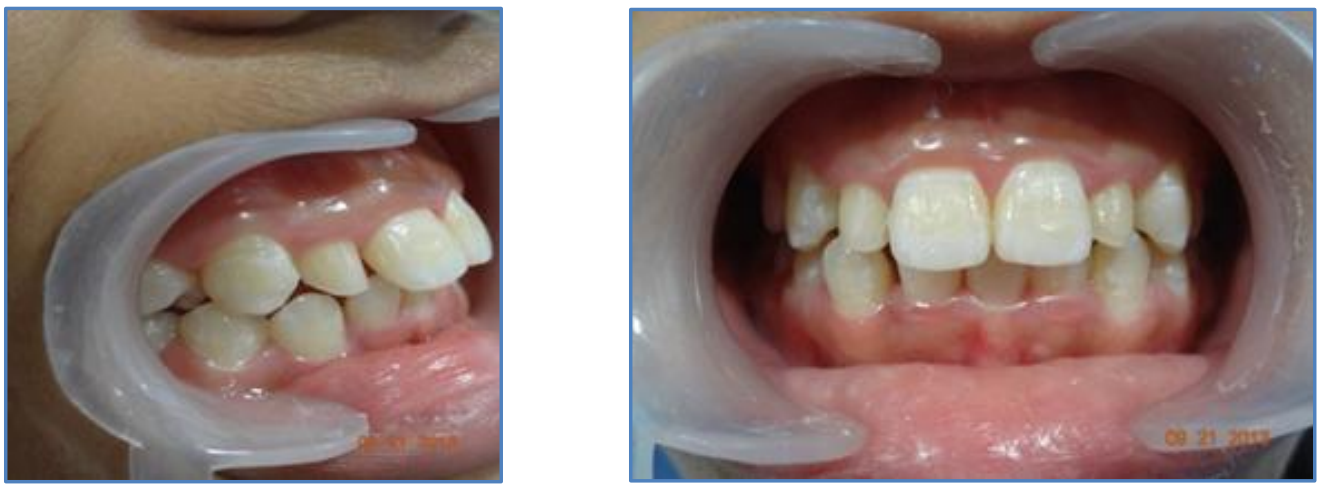

Figure 3: Tooth Preparation

Cementation of Veneers: The concept of porcelain etching was introduced by Horn in 1983. [3] Etching is traditionally carried out using commercially available.

- $10 \%$ ammonium di-fluoride gel for glass ceramics,

- $\quad 2-10 \%$ hydrofluoric acid gel for other ceramics.

Shahverdi et al in his study said that air abrasion with 50 micro meter aluminium oxide particles cannot provide mechanically retentive surfaces as satisfactorily as etching with Hydrofluoric acid. [4]

According to McLean (1980), etching is indispensable, since this eliminates superficial micro cracks as well as certain surface flaws on the internal surface by a process of partial dissolution. Impregnation by the bonding resin will provide reinforcement and better distribution of stress; this would explain the improved mechanical properties of ceramics after bonding. Etching also helps to enhance wettability and complete the cleaning process.

A fine layer of silane coupling agent is painted over the internal surface of the laminate veneer (IPS Empress, IVOCLAR VIVADENT, LIECHTENSTEIN) once it has been etched so as to create a chemical bond between the ceramic and composite. [5]

The tooth was etched with 37\% phosphoric acid for 15-20 seconds. A layer of Adper Single bond 2 adhesive(3M ESPE, U.S.A) was applied on the tooth and the luting cement used was Variolink II (IVOCLAR VIVADENT, LIECHTENSTEIN), a dual cure veneer cement. The etched and cleansed teeth should be isolated interdentally with very fine strips to avoid composite spilling over adjacent teeth.

The veneers are placed into position and cured with Bluephase LED light (IVOCLAR VIVADENT). Finishing and polishing of the veneer was done using diamond burs (S. S. WHITE) and the margins were polished using Optrapol (IVOCLAR VIVADENT).

Occlusion was checked to avoid and protrusive and lateral excursive interferences using the help of an articulating paper. 


\section{CASE REPORT}
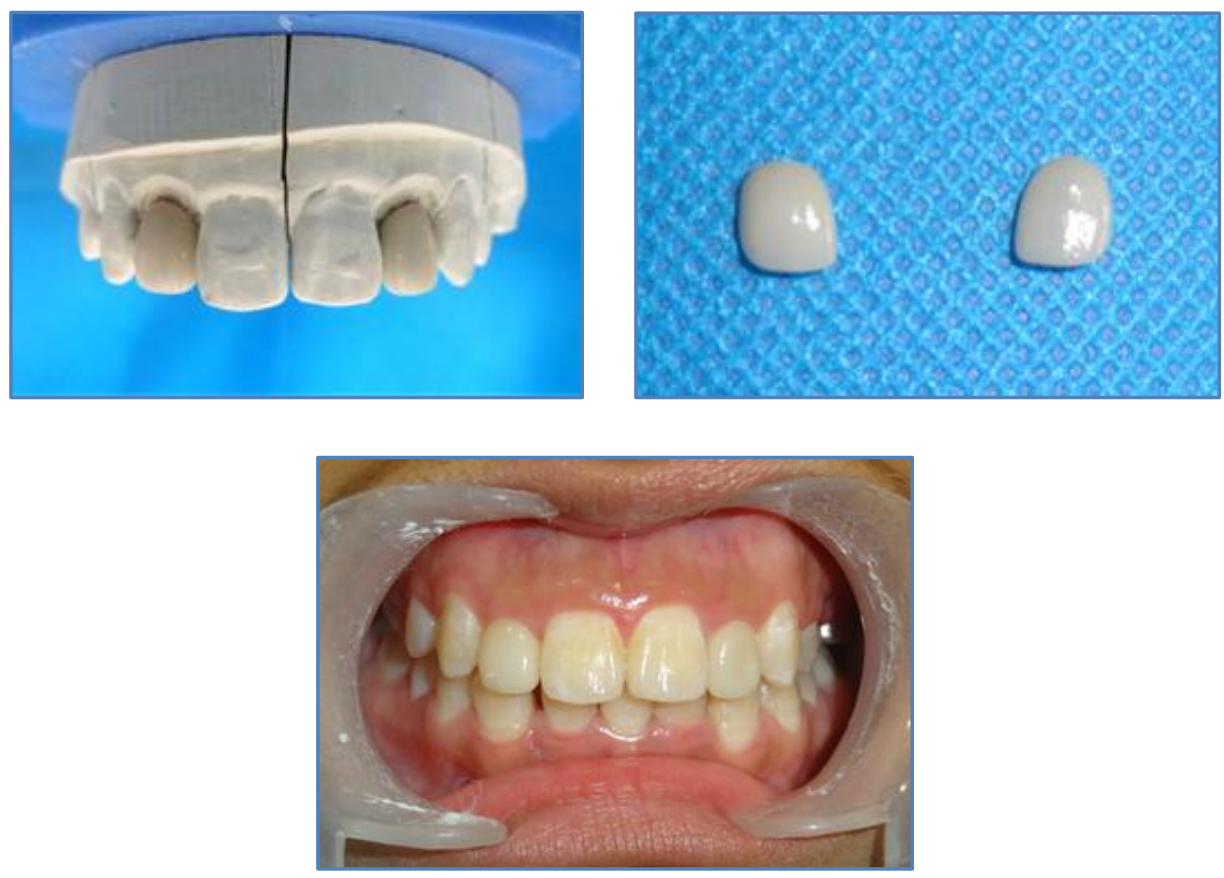

\section{Figure 4: Post cementation of veneers}

DISCUSSION: Even though dentin bonding materials are improving and emerging clinical research is encouraging, intact enamel provides the most reliable substrate for etched porcelain restorations.

Preparations can be designed with supragingival finish lines and can be virtually invisible. Porcelain veneers have demonstrated long term clinical success. A survival rate of $99 \%$ was observed for veneers with preparation confined to enamel and $94 \%$ with enamel only at the margins at follow ups. [6]

Beier U., Kapferer I., and Dumfahrt H in their study quoted that porcelain veneers offer a predictable and successful outcome with an estimated survival rate of $93.5 \%$ over 10 years. [7]

Fredeani in his study retrospectively evaluated 182 veneers over a period of 12 years and found an associated success rate of $94.4 \%$ at 12 years. [8]

Thus, following of evidence based principles and modern bonding techniques have made porcelain veneers a predictable treatment modality to enhance dental aesthetics.

\section{REFERENCES:}

1. Tseng EY, Cooley Rl, Evans JG. Porcelain to Dentin bond strength with a dent in adhesive. J Esthet Dent.1992 Jul-Aug; 4 (4): 131-3.

2. Shetty A, Kaiwar A, Shubhashini N, Ashwini P, Naveen D, Adarsha M. et al. Survival rates of porcelain laminate restorations based on different incisal preparation designs: An analysis. J Conserv Dent. 2001 Jan; 14 (1): 10-15.

3. Horn HR. Porcelain laminate veneers bonded to etched enamel.Dent Clin North Am.1983 Oct; 27 (4): 671-84.

4. Shahverdi S, Canay S, Sahin E, Bilge A. Effects of different surface treatment methods on bond strength of composite resin to porcelain. J Oral Rehabil.1998 Sep; 25 (9): 699-705. 


\section{CASE REPORT}

5. Gurel G. The science and art of porcelain laminate veneers. Quintessence Int.2003: 231-332.

6. Gurel G, Sesma N, Calamita MA, Coachman C, Morimoto S. Influence of enamel preservation on failure rates of porcelain laminate veneers. Int J Periodontics Restorative Dent. 2013 Jan-Feb; 33 (1): 31-9.

7. Bier US, Kapferer I, Burtscher D, Dumfahrt H. Clinical performance of porcelain laminate veneers for upto 20 years. Int J Prosthodont. 2012 Jan-Feb; 25 (1): 79-85.

8. Fradeani M, Redemagni M, Corrado M. Porcelain laminate veneers: 6-12 year clinical evaluation-A retrospective study. Int J Periodontics Restorative Dent. 2005 Feb; 25 (1): 9-17.

\section{AUTHORS:}

1. Arshin Hotchandani

2. Hina Desai

3. N. J. Nirmal

\section{PARTICULARS OF CONTRIBUTORS:}

1. Post Graduate Student, Department of Prosthodontics, Crown and Bridge, Manubhai Patel Dental College, Vadodara.

2. Professor and HOD, Department of Orthodontics and Dentofacial Orthopedics, Manubhai Patel Dental College, Vadodara.

3. Professor and HOD, Department of Prosthodontics, Crown and Bridge, Manubhai Patel Dental College, Vadodara.

\section{NAME ADDRESS EMAIL ID OF THE CORRESPONDING AUTHOR:}

Dr. Arshin Hotchandani, 401, Madhuban Apartments, Behind Iscon Heights, Gotri Road, Vododara-390021, Gujarat, India.

Email: arshin.hotchandani@gmail.com

Date of Submission: 11/08/2014. Date of Peer Review: 12/08/2014. Date of Acceptance: 20/08/2014. Date of Publishing: 27/08/2014. 